\title{
Estudo anatômico de folha e caule de Pereskia aculeata Mill. (Cactaceae)
}

\author{
M.R. Duarte*, S.S. Hayashi \\ Laboratório de Farmacognosia, Departamento de Farmácia, Universidade Federal do Paraná, \\ Rua Pref. Lothário Meissner 3400, 80210-170, Curitiba, PR, Brasil
}

\begin{abstract}
RESUMO: Pereskia aculeata Mill. (Cactaceae) é uma trepadeira arbustiva conhecida comumente como ora-pro-nobis. Apresenta elevado teor de mucilagem e proteína, sendo empregada na indústria alimentícia e farmacêutica. Na medicina popular,éutilizada externamente como emoliente. Este trabalho teve por objetivo estudar a anatomia foliar e caulinar da planta, a fim de fornecer informações complementares à sua identificação e aplicáveis ao seu controle de qualidade. Folhas adultas e fragmentos de caules foram fixados, seccionados à mão livre e corados com azul de astra e fucsina básica ou com azul de toluidina. Testes histoquímicos e análise ultra-estrutural de superfície foram realizados. A folha é simples e elíptica. Possui epiderme uniestratificada, estômatos paracíticos em ambas as faces, mesofilo que tende a ser dorsiventral, contendo numerosas drusas de oxalato de cálcio e células isodiamétricas grandes com conteúdo mucilaginoso. A nervura central é percorrida por um feixe vascular colateral em arco aberto. O pecíolo tem secção plano-convexa e um feixe colateral em formato de arco fechado. O caule, em estrutura secundária incipiente, possui epiderme unisseriada, colênquima angular, parênquima cortical com muitos amiloplastos, calotas de fibras perivasculares e organização vascular colateral. No córtex e na medula, são observadas numerosas cavidades com conteúdo mucilaginoso e drusas de oxalato de cálcio, estas também presentes no floema.
\end{abstract}

Unitermos: Pereskia aculeata, Cactaceae, emoliente, mucilagem, planta medicinal.

ABSTRACT: “Anatomical study of the leaf and stem of Pereskia aculeata Mill. (Cactaceae)". Pereskia aculeata Mill. (Cactaceae) is a climbing shrub commonly known as Barbados gooseberry. It has high mucilage and protein content and it is employed in the food and pharmaceutical industry. In traditional medicine, $P$. aculeata is used externally as emollient. This work aimed to study the leaf and stem anatomy of this plant, in order to supply additional information for its identification and quality control. Mature leaves and stem fragments were fixed, freehand sectioned and stained either with astra blue and basic fuchsine or toluidine blue. Histochemical tests and ultrastructure analysis were carried out. The leaf is simple and elliptical, and has uniseriate epidermis, paracytic stomata on both surfaces, dorsiventral-like mesophyll, several druses of calcium oxalate and large isodiametric cells containing mucilage. In the midrib a collateral bundle in open arc is embedded. The petiole exhibits a plain-convex transection and a collateral bundle in closed arc shape. The stem, in incipient secondary growth, has uniseriate epidermis, angular collenchyma, cortical parenchyma with many amiloplasts, perivascular fibre caps and collateral vascular organization. In the cortex and pith, numerous cavities containing mucilage and druses of calcium oxalate are seen, the latter also in the phloem.

Keywords: Pereskia aculeata, Cactaceae, emollient, mucilage, medicinal plant.

\section{INTRODUÇÃO}

Pereskiaaculeata Mill.éuma espéciepertencente à subfamília Pereskioideae, considerada detentora do maior número de caracteres primitivos da família Cactaceae (Mauseth, 1999). Representantes do gênero ocorrem somente em regiões mésicas ou levemente áridas e consistem de plantas com caules finos, sublenhosos ou lenhosos, onde se inserem folhas largas com poucos espinhos na base e surgem flores terminais solitárias ou em cimeiras curtas (Cronquist, 1981; Manke, 1998).
Diferentes espécies de Pereskia têm sido investigadas sob variados aspectos, tais como relativos à identificação do alcalóide alucinógeno mescalina em $P$. corrugata Cutak e P. tampicana F.A.C. Weber (Doetsch et al., 1980), à citotoxicidade de P. bleo (Kunth) DC. (Gupta et al., 1996), à composição da mucilagem (Pinto et al., 1994) e à diversidade genética (Nassar et al., 2002) de $P$. guamacho F.A.C. Weber, à identificação de saponinas em P. grandifolia Haw. (Sahu et al., 1974), e de esteróides (Salt et al., 1987) e polissacarídeos (Sierakowski et al., 1990) em $P$. aculeata. 
Denominada comumente de ora-pro-nobis, trepadeira-limão e groselha-de-barbados, $P$. aculeata é uma trepadeira semilenhosa, que pode atingir $10 \mathrm{~m}$ de altura, com ramos longos e espinhos na axila das folhas elípticas e carnosas (Alzugaray; Alzugaray, 1988; Lorenzi; Souza, 1995; Manke, 1998). Essa espécie e P. grandifolia apresentam alto teor de mucilagem, sendo empregadas externamente como emoliente na medicina popular e consumidas como fonte alimentar (Cruz, 1995). Em virtude da presença do biopolímero arabinogalactana e do elevado conteúdo protéico, essas plantas têm despertado o interesse das indústrias alimentícia e farmacêutica (Mercê et al., 2001). Portanto, este trabalho teve por objetivo estudar a anatomia foliar e caulinar de Pereskia aculeata Mill. (Cactaceae), a fim de fornecer informações complementares à identificação da mesma, aplicáveis ao seu controle de qualidade.

\section{MATERIAL E MÉTODOS}

O material botânico foi coletado de exemplares cultivados no Horto de Plantas Medicinais, do Departamento de Farmácia, da Universidade Federal do Paraná, cujas coordenadas são 2526'45”'S e 49¹4’25”W e cuja altitude aproximada é de $900 \mathrm{~m}$, em março de 2003. A exsicata identificada está depositada no Museu Botânico Municipal de Curitiba, com o registro MBM 89665.

Folhas adultas e fragmentos de caules, obtidos a partir de 10cm do ápice caulinar, foram fixados em FAA 70 (Johansen, 1940), armazenados em etanol a 70\% (Berlyn; Miksche, 1976) e seccionados nos sentidos transversal e longitudinal, à mão livre. Os cortes foram submetidos à dupla coloração com azul de astra e fucsina básica (Roeser, 1962) ou com azul de toluidina (O’Brien et al., 1965). Testes histoquímicos foram também realizados, empregando-se as soluções de floroglucina clorídrica (Sass, 1951) para elementos lignificados, lugol (Berlyn; Miksche, 1976) para amido, Sudan IV (Foster, 1949) para substâncias lipofílicas, azul de metileno (Oliveira; Akisue, 1989) para mucilagem, cloreto férrico (Johansen, 1940) para compostos fenólicos, e ácido sulfúrico (Oliveira; Akisue, 1989) para evidenciar a natureza química dos cristais. O registro das observações foi realizado por meio de diagramas e fotomicrografias em microscópio fotônico Olympus BX40 acoplado à câmara clara e à unidade de controle PM20.

Para a análise ultra-estrutural de superfície (Souza, 1998), folhas adultas fixadas foram desidratadas em série etanólica crescente e pelo ponto crítico por meio do equipamento Bal-Tec CPD030, metalizadas em Balzers SCD030 e observadas em microscópio eletrônico de varredura Jeol JSM6360LV.

\section{RESULTADOS}

Pereskia aculeata Mill. (Figura 1) apresenta folha simples, simétrica, elíptica e de textura coriácea, com cerca de $7 \mathrm{~cm}$ de comprimento e $3 \mathrm{~cm}$ de largura. $\mathrm{O}$ ápice é agudo-acuminado, a base aguda, a margem inteira e a nervação hipódroma, onde somente a nervura central é nítida. O pecíolo é curto e duas a seis folhas agrupam-se em ramos laterais alternos e apresentam espinho axilar.

\section{Anatomia foliar}

O limbo, em vista frontal, possui células epidérmicas com paredes anticlinais poligonais, espessadas e estômatos paracíticos em ambas as faces (Figuras 2, 3, 8). Estes estão inseridos no mesmo nível das células circunvizinhas. Cutícula relativamente espessada e estriada (Figura 8) reveste a epiderme uniestratificada. O mesofilo tende a ser dorsiventral (Figuras 4, 5), sendo constituído por cerca de quatro a oito camadas de parênquima paliçádico atípico, cujas células são largas, comparativamente curtas e pouco diferenciadas do parênquima esponjoso. Este é multiestratificado, forma pequenos espaços intercelulares e representa aproximadamente $50 \%$ da altura do clorênquima. Numerosos feixes vasculares colaterais de pequeno porte, envoltos por uma bainha parenquimática, distribuemse no mesofilo. Idioblastos com drusas de oxalato de cálcio e grandes células isodiamétricas com conteúdo mucilaginoso são observados no clorênquima (Figura 5).

A nervura central (Figuras 4, 6) é praticamente plana na face adaxial e levemente convexa na abaxial. A epiderme exibe as mesmas características do limbo e o parênquima paliçádico não se interrompe junto à face adaxial. Um feixe vascular colateral (Figuras 6, 7) em formato de arco aberto percorre a nervura e é envolvido por uma bainha amilífera. No xilema, os elementos traqueais dispõem-se de modo enfileirado, separados por células parenquimáticas. No floema, os elementos crivados acompanhados de células parenquimáticas especializadas e não especializadas formam cordões lado a lado. A zona cambial pode ser distinguida junto aos cordões floemáticos. Calotas de células com paredes

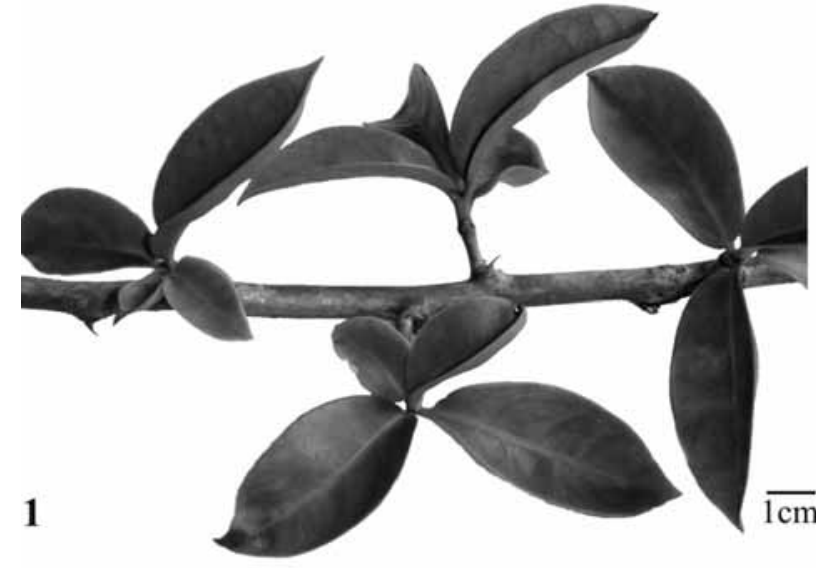

Figura 1. Pereskia aculeata Mill. (Cactaceae): 1. detalhe de um ramo vegetativo, evidenciando a disposição das folhas e a presença de espinhos. 

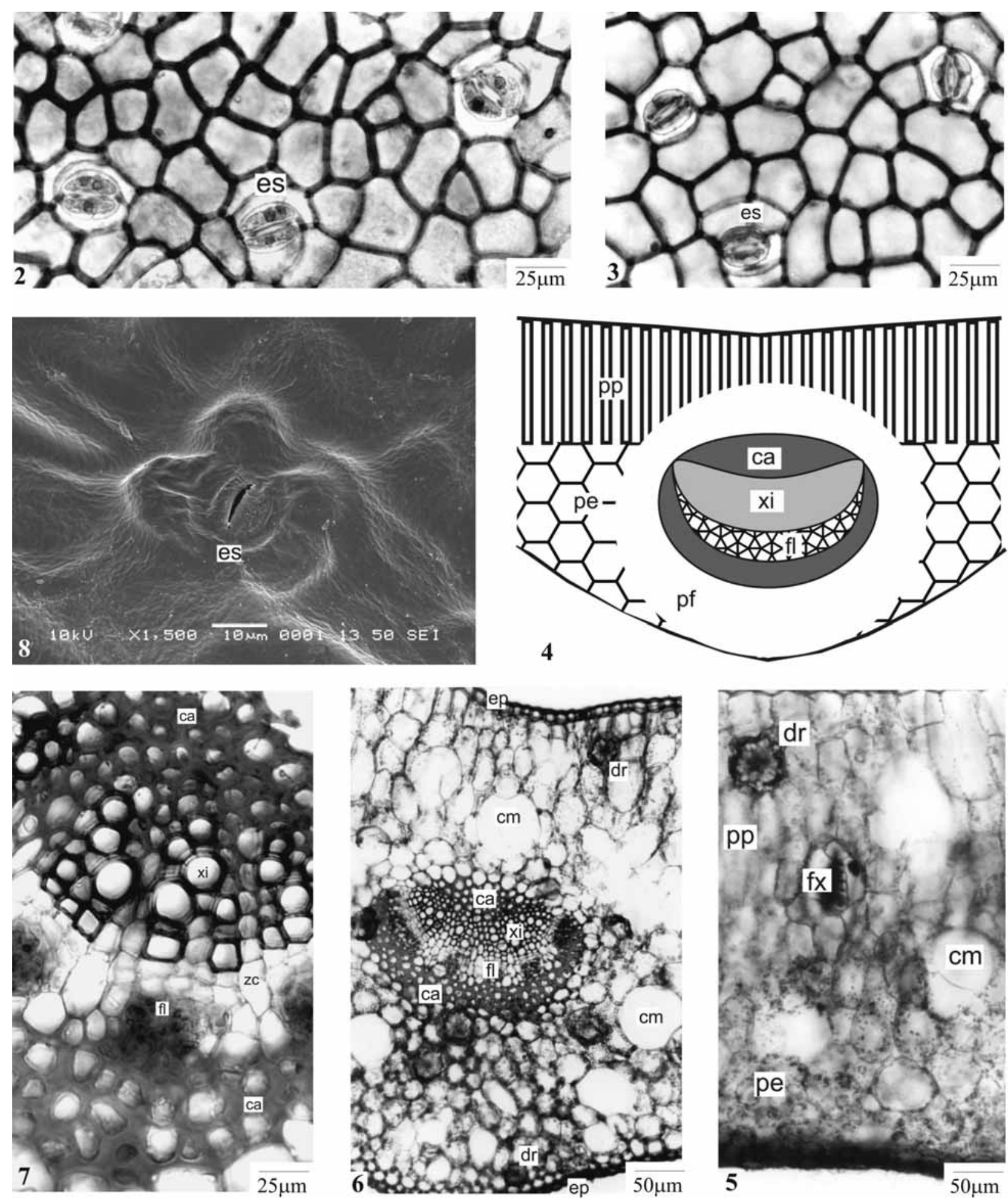

Figuras 2-8. P. aculeata: 2 e 3. faces epidérmicas adaxial e abaxial, respectivamente; 4. diagrama da organização da nervura central e parte do limbo; 5. secção transversal do limbo, indicando feixe vascular de pequeno porte; 6 . nervura central, em secção transversal, onde se notam células grandes contendo mucilagem, drusas e um feixe vascular em arco aberto; 7. detalhe do feixe vascular colateral da nervura central; 8. detalhe de um estômato e da epiderme, onde se observa cutícula estriada (MEV). ca - calota de células de paredes espessadas, $\mathrm{cm}$ - célula com mucilagem, dr - drusa, ep - epiderme, es - estômato, fl - floema, fx - feixe vascular, pe - parênquima esponjoso, pf - parênquima fundamental, pp - parênquima paliçádico, xi - xilema, zc - zona cambial. 
espessadas e não lignificadas apõem-se ao xilema e ao floema.

O pecíolo (Figuras 9, 10), em secção transversal, possui formato plano-convexo. A epiderme é unisseriada, o parênquima fundamental apresenta diversos idioblastos com drusas de oxalato de cálcio e células grandes contendo mucilagem, e é percorrido por um feixe vascular colateral em formato de arco fechado. Uma bainha incompleta de células com parede espessada em diferentes estágios de lignificação envolve o feixe vascular.

\section{Anatomia caulinar}

O caule mostra secção transversal circular (Figura 11). Em estrutura secundária incipiente, apresenta epiderme uniestratificada revestida por cutícula espessada (Figura 12). Subjacentemente, nota-se uma faixa contínua de colênquima angular, formada por cerca de cinco estratos. No parênquima cortical, observam-se numerosos amiloplastos e cloroplastos. Calotas de fibras perivasculares e esparsas fibras isoladas, de paredes espessadas e lúmen reduzido, localizam-se junto ao floema. Este e o xilema, que é totalmente lignificado, são percorridos por raios estreitos. Os elementos traqueais dispõem-se isoladamente ou em pequenos grupos no xilema (Figuras 13, 14). A medula ocupa considerável volume do caule (Figuras 13,15) e é formada por células parenquimáticas que contêm amiloplastos. No córtex e na medula, são observados idioblastos com drusas de oxalato de cálcio e cavidades relativamente grandes contendo mucilagem (Figuras 12, 13, 15), os primeiros também no floema (Figura 14).

\section{DISCUSSÃO}

A constatação de células epidérmicas dispostas em estrato único e com paredes anticlinais poligonais em ambas as faces coincide com o verificado em P. grandifolia Haw. (Farago et al., 2004) e corresponde parcialmente com o resultado da anatomia foliar comparada de quatro espécies de Pereskia, relatado por Garcia et al. (2000). Segundo esses autores, $P$. aculeata Mill., $P$. guamacho F.A.C. Weber, P. bleo (Kunth) DC. e P. zinniiflora DC. possuem epiderme uniestratificada. No entanto, células epidérmicas com contorno ondulado em vista frontal são observadas nas duas últimas espécies e na face abaxial de P. aculeata.

A família Cactaceae se caracteriza por possuir estômatos paracíticos e anomocíticos (Cronquist, 1981), e a espécie em estudo demonstra a presença do primeiro tipo em folha anfiestomática, similar aos resultados obtidos por Garcia et al. (2000) para P. aculeata e por Farago et al. (2004) para $P$. grandifolia. Comparativamente, estômatos ciclocíticos e paralelocíticos são também mencionados para $P$. bleo, $P$. guamacho e $P$. zinniiflora (Garcia et al., 2000).

De modo similar às características apontadas por
Mauseth e Landrum (1997), para quem o gênero possui mesofilo consistindo de parênquima paliçádico pouco diferenciado do esponjoso e destituído de hipoderme, a espécie analisada mostra clorênquimas pouco distinguíveis, que levam à classificação do mesofilo como tendendo a dorsiventral. P. grandifolia (Farago et al., 2004) e as espécies investigadas por Garcia et al. (2000), excetuando-se P. guamacho que possui mesofilo isobilateral, apresentam o mesmo padrão.

As características estruturais da nervura central observadas neste trabalho divergem parcialmente dos resultados de Garcia et al. (2000) para a mesma espécie, já que esses autores mencionam dois a quatro feixes vasculares acompanhados de esclerênquima na nervura. Em relação a $P$. grandifolia, planta correlata que recebe a mesma denominação comum e é empregada com os mesmos fins, a nervura central com convexidade proeminente junto à face abaxial (Farago et al., 2004) mostra-se distinta de P. aculeata.

Pecíolo com secção plano-convexa é descrito para $P$. aculeata, $P$. guamacho e $P$. zinniiflora, enquanto que contorno circular é mencionado em $P$. bleo (Garcia et al., 2000). As características relativas ao tipo e formato do feixe vascular na espécie em estudo se enquadram na investigação de $P$. aculeata apresentada por Garcia et al. (2000), embora esses autores tenham mencionado arco aberto para ilustração condizente com arco fechado. Adicionalmente, Cronquist (1981) registra que células contendo mucilagem são comumente encontradas em membros da família, o que confere com o verificado na anatomia foliar de $P$. aculeata e de outras espécies do gênero (Garcia et al., 2000; Farago et al., 2004).

A organização caulinar segue o estabelecido para as Cactaceae e a inobservância de hipoderme no caule é mencionada para Pereskia (Metcalfe; Chalk, 1950). Ainda, segundo esses autores, a sustentação mecânica do eixo caulinar é favorecida pela presença de cordões de elementos com paredes espessadas junto à parte periférica do floema. Esses elementos correspondem às fibras lignificadas agrupadas ou isoladas apostas ao floema descritas na espécie estudada. Na opinião de Mauseth (1999), estruturas lignificadas em Pereskia são coerentes com a adaptação do gênero a ambientes mésicos a levemente áridos. A ausência de esclerênquima é característica de plantas xéricas, que podem se contrair durante períodos de seca e evitar os danos decorrentes de embolismo.

Diferindo de outras Cactaceae, que apresentam feixes vasculares na medula, os quais favorecem o armazenamento de água e amido, em Pereskia os mesmos estão ausentes e a medula pode representar metade do volume caulinar (Mauseth, 1993), como evidenciado em P. aculeata.

A ocorrência de idioblastos com drusas está em conformidade com o verificado nas quatro espécies estudadas por Garcia et al. (2000) e em P. grandifolia (Farago et al., 2004). Cristais de oxalato de cálcio são 

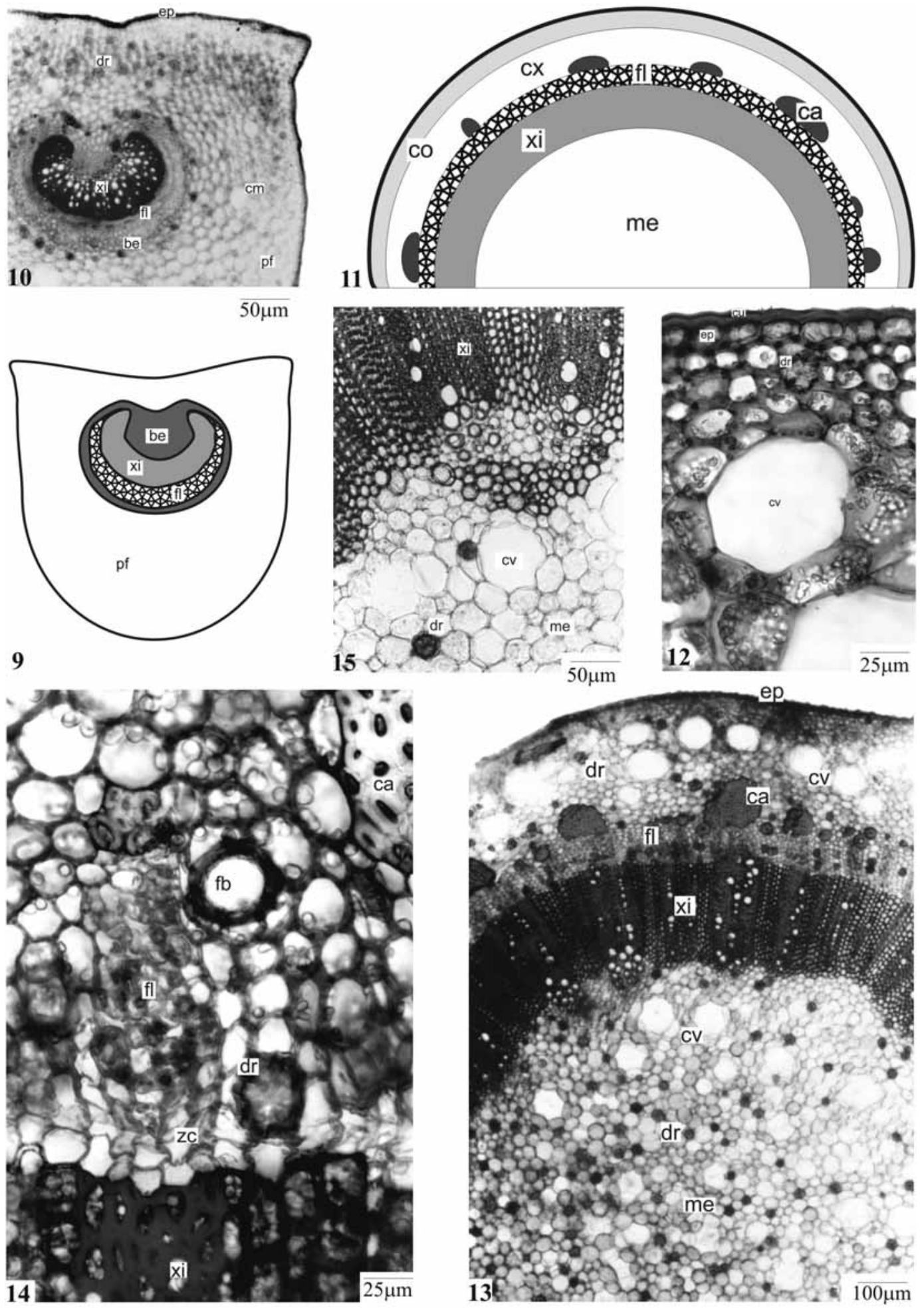

Figuras 9-15. P. aculeata: 9. diagrama do pecíolo; 10. pecíolo em secção transversal, onde se evidencia um feixe vascular colateral em arco fechado; 11. diagrama da organização caulinar; 12. cavidade contendo mucilagem no córtex do caule; 13 . secção transversal do caule, em estrutura secundária incipiente; 14 . detalhe do sistema vascular, indicando a zona cambial; 15. parte do xilema e da medula do caule, mostrando drusas e cavidades com conteúdo mucilaginoso. be - bainha esclerenquimática, ca - calota de fibras perivasculares, $\mathrm{cm}$ - célula com mucilagem, co - colênquima, cu - cutícula, cv - cavidade contendo mucilagem, cx - córtex, dr - drusa, ep - epiderme, fb - fibra, fl - floema, me - medula, pf - parênquima fundamental, xi - xilema, zc - zona cambial. 
freqüentes na família (Metcalfe; Chalk, 1950; Cronquist, 1981) e a essas substâncias ergásticas são atribuídas diferentes funções, como defesa mecânica à herbivoria, suporte estrutural, reserva de cálcio e manutenção do equilíbrio iônico (Franceschi; Horner Jr., 1980).

Cientes de que o arranjo dos idioblastos cristalíferos e das estruturas secretoras de mucilagem no caule pode ser significativo na caracterização de grupos na família, Metcalfe e Chalk (1950) procuram correlacionar diversos gêneros com diferentes categorias. A espécie em questão apresenta simultaneamente cavidades contendo mucilagem e idioblastos com drusas, de modo diverso de alguns representantes de Pereskia, cujas células cristalíferas podem ter uma localização subepidérmica definida e não ser acompanhadas de estruturas contendo mucilagem.

Os caracteres observados neste trabalho, tais como ausência de hipoderme e de feixes vasculares no córtex ena medula caulinares, elementos traqueais isolados ou em pequenos grupos no caule, feixes vasculares não acompanhados de esclerênquima na nervura central, são considerados primitivos em Cactaceae por Mauseth e Landrum (1997), e confirmam a posição hierárquica do gênero dentro da família. De acordo com Altesor et al. (1992), essa posição é corroborada também com aspectos fisiológicos, uma vez que representantes de Pereskia mantêm metabolismo fotossintético ancestral $\mathrm{C}_{3}$, em oposição às demais Cactaceae que apresentam padrão CAM típico, avaliado como mais evoluído.

\section{CONCLUSÕES}

O estudo anatômico de folha e caule de $P$. aculeata apresenta caracteres estruturais que contribuem na identificação da planta medicinal e que podem ser aplicáveis ao seu controle de qualidade. Todavia, devem ser considerados em conjunto, levando-se em conta que alguns caracteres são comuns a outros representantes do gênero e isoladamente não apresentam valor taxonômico para sua diferenciação, uma vez que espécies em grupos muito próximos apresentam caracteres estruturais e compostos químicos em comum.

\section{AGRADECIMENTOS}

Os autores são gratos aos taxonomistas Dr. Gert Hatschbach e Juarez Cordeiro, do Museu Botânico Municipal de Curitiba, pela identificação da espécie.

\section{REFERÊNCIAS}

Altesor A, Ezcurra E, Silva C 1992. Changes in the photosynthetic metabolism during the early ontogeny of 4 cactus species. Acta Oecol-Int J Ecol 13: 777-85.

Alzugaray D, Alzugaray K 1988. Enciclopédia de plantas brasileiras. São Paulo: Três.

Berlyn GP, Miksche JP 1976. Botanical microtechnique and cytochemistry. Ames: Iowa State University.

Cronquist A 1981. An integrated system of classification of flowering plants. New York: Columbia University Press.

Cruz GL 1995. Dicionário das plantas úteis do Brasil. 5.ed. Rio de Janeiro: Bertrand Brasil.

Doetsch PW, Cassady JM, McLaughlin JL 1980. Cactus alkaloids. XL. Identification of mescaline and other $\beta$ phenethylamines in Pereskia, Pereskiopsis and Islaya by use of fluorescamine conjugates. $J$ Chromatogr 189: 79-85.

Farago PV, Takeda IJM, Budel JM, Duarte MR 2004. Análise morfo-anatômica de folhas de Pereskia grandifolia Haw., Cactaceae. Acta Farm Bonaerense 23: 323327.

Foster AS 1949. Practical plant anatomy. $2^{\text {nd }}$ ed. Princeton: D.Van Nostrand.

Franceschi VR, Horner Jr HT 1980. Calcium oxalate crystals in plants. Bot Rev 46: 361-427.

Garcia M, Lapp M, Castro M, Torrecilla P 2000. Anatomia foliar comparada de cuatro especies del genero Pereskia (Plum.) Miller (Cactaceae). Ernstia 10: 27-41.

Gupta M, Monge A, Karikas GA, Cerain AI, Solis PN, Leon E, Trujillo M, Suarez O, Wilson F, Montenegro G, Noriega Y, Santana AI, Correa M, Sánchez C 1996. Screening of Panamanian medicinal plants for brine shrimp toxicity, crown gall tumor inhibition, cytotoxicity and DNA intercalation. Int J Pharmacogn 34: 19-27.

Johansen DA 1940. Plant microtechnique. New York: McGrawHill Book.

Lorenzi H, Souza HM 1995. Plantas ornamentais no Brasil: arbustivas, herbáceas e trepadeiras. Nova Odessa: Plantarum.

Manke E 1998. Cactus. s.l.: Barron's.

Mauseth JD 1993. Water-storing and cavitation-preventing adaptations in wood of cacti. Ann Bot 72: 81-89.

Mauseth JD 1999. Anatomical adaptations to xeric conditions in Maihuenia (Cactaceae), a relictual, leaf-bearing cactus. J Plant Res 112: 307-15.

Mauseth JD, Landrum JV 1997. Relictual vegetative anatomical characters in Cactaceae: the genus Pereskia. J Plant Res 110:55-64.

Mercê ALR, Landaluze JS, Mangrich AS, Szpoganicz B, Sierakowski MR 2001. Complexes of arabinogalactan of Pereskia aculeata and $\mathrm{Co}^{2+}, \mathrm{Cu}^{2+}, \mathrm{Mn}^{2+}$ and $\mathrm{Ni}^{2+}$. Bioresour Technol 76: 29-37.

Metcalfe CR, Chalk L 1950. Anatomy of dicotyledons: leaves, stem, and woods in relation to taxonomy with notes on economic uses. Oxford: Clarendon. v. 1

Nassar JM, Hamrick JL, Fleming TH 2002. Allozyme diversity and genetic structure of the leafy cactus (Pereskia guamacho Cactaceae). J Heredity 9: 193-200.

O’Brien TP, Feder N, McCully ME 1965. Polychromatic staining of plant cell walls by toluidine blue O. Protoplasma 59: 368-73.

Oliveira F, Akisue G 1989. Fundamentos de farmacobotânica. Rio de Janeiro: Atheneu.

Pinto GL, Moncada NP, Martínez M, Gotera OG, Rivas C, Ocando E 1994. Composition of Pereskia guamacho gum exudates. Biochem Syst Ecol 22: 291-295.

Roeser KR 1962. Die Nadel der Schwarzkiefer-Massenprodukt und Kunstwerk der Natur. Mikrokosmos 61: 33-36. 
Sahu NP, Banerji N, Chakravarti RN 1974. A new saponin of oleanolic acid from Pereskia grandifolia. Phytochemistry 13: 529-530.

Salt TA, Tocker JE, Adler JH 1987. Dominance of $\Delta^{5}$-sterols in eight species of the Cactaceae. Phytochemistry 26: 731-733.

Sass JE 1951. Botanical microtechnique. $2^{\text {nd }}$ ed. Ames: Iowa State College.

Sierakowski MR, Gorin PAJ, Reicher F, Corrêa JBC 1990. Locationof $O$-acetylgroupsintheheteropolysaccharide of the cactus Pereskia aculeata. Carbohydr Res 201: 277-284.

Souza W 1998. Técnicas básicas de microscopia eletrônica aplicadas às Ciências Biológicas. Rio de Janeiro: Sociedade Brasileira de Microscopia Eletrônica. 